\title{
Development and validation of reverse phase high performance liquid chromatographic method for the estimation of metoprolol tartrate tablets $50,100 \mathrm{mg}$
}

\author{
B. Nageswara Rao' ${ }^{1}$, P. Venkata Rao ${ }^{1}$, A. Lakshmana Rao ${ }^{2}$ \\ 1Dr. Reddy's Laboratories Ltd, VSEZ, Duvvada, Visakhapatnam. \\ ${ }^{2}$ Vallabhaneni Venkatadri Institute of Pharmaceutical sciences, Gudlavalleru, Krishna Dist.
}

*Corresponding author e-mail: nagumph@gmail.com

\begin{abstract}
:
A new simple, rapid, specific, precise, accurate and reproducible reverse phase high performance liquid chromatographic stability indicating method had been developed and validated for quantitative determination of Metoprolol in Metoprolol tartrate tablets. The separation method developed produce acceptable values of recovery. The chromatogram developed has well resolved peak of Metoprolol without any interference. Sample preparation was assured by powdered method. Separation occurred on symmetry $\mathrm{C}_{18} \mathrm{RP}$ column $(150 \times 4.6 \mathrm{~mm}) 5 \mu \mathrm{m}$ with a mobile phase of phosphate buffer $\mathrm{pH}-3.0$ and Acetonitrile $(80: 20 \% \mathrm{v} / \mathrm{v})$ and detection at $275 \mathrm{~nm}$ in $0.1 \mathrm{~N} \mathrm{HCl}$ as diluents. The standard curve was linear over the concentration range of 100.52-603.11 ppm. All the degradation peaks were resolved effectively using developed method with different retention times. The developed method was validated according to ICH Q2 R1 guidelines. The lower limit of quantification for Metoprolol tartrate was 186ppm. As the method could effectively separates the degradation products from active ingredients, it can be used for industrial analysis purpose for the analysis of Metoprolol tartrate tablet BP 50,100 mg.
\end{abstract}

Key words: Metoprolol Tartrate, Analytical Method development, Analytical method validation.

\section{INTRODUCTION}

Metoprolol tartrate is available as 50- and 100-mg tablets for oral administration. Metoprolol tartrate USP is a white, practically odorless, crystalline powder with a molecular weight of 684.82 . It is very soluble in water; freely soluble in methylene chloride, in chloroform, and in alcohol; slightly soluble in acetone; and insoluble in ether.

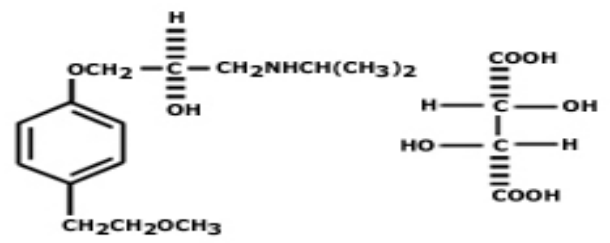

Fig. 1.1 Structure of Metoprolol tartrate

\section{MATERIALS AND METHODS MATERIALS}

Metoprolol tartrate WRS (potency-99.7\%), Milli-Q water, Methanol HPLC grade, Acetonitrile HPLC grade, Hydrochloric acid, Ortho phosphoric acid, Potassium dihydrogen phosphate AR, Ammonium acetate AR, Acetic acid.

METHOD AND
OPTIMIZATION
TRAILS
Trail-1: Metoprolol tartrate tablets HPLC
method development by using RS-
methodology of Metoprolol tartrate tablets
given in BP.




\section{Parameters:}

1. Column: Symmetry $C_{18}(150 \times 3.9) \mathrm{mm}, 5 \mu$

2. Flow rate: $1.0 \mathrm{~mL} / \mathrm{min}$

3. Injection volume: $25 \mu \mathrm{L}$

4. Wave length: $275 \mathrm{~nm}$

5. Column temperature: $25 \mathrm{oC}$

6. Mobile phase: $50 \mathrm{ml}$ of $1 \mathrm{M}$ monobasic sodium phosphate (NaH2Po4) $+8.0 \mathrm{ml}$ of phosphoric acid in $900 \mathrm{ml}$ of water. Adjust pH 3.0 with $1 \mathrm{M} \mathrm{OPA}$ or $1 \mathrm{M} \mathrm{NaH2Po4.}$ Make up to $1000 \mathrm{ml}$ with water.

7. Mix buffer and acetonitrile in ratio $75: 25 \mathrm{v} / \mathrm{v}$

8. Diluent 1: mobile phase

9. Diluent 2: $0.1 \%$ OPA and methanol in ratio $75: 25 \mathrm{v} / \mathrm{v}$

\section{Standard preparation:}

$50.66 \rightarrow 100 \mathrm{ml}, 5 \mathrm{ml} \rightarrow 50 \mathrm{ml}$ with diluent- 1

$50.83 \rightarrow 100 \mathrm{ml}, 5 \mathrm{ml} \rightarrow 50 \mathrm{ml}$ with diluent- 2

\section{Test preparation:}

Placebo: $339.6 \mathrm{mg}$ placebo powder of $50 \mathrm{mg}$ tablets is taken in $500 \mathrm{ml}$ volumetric flask. $350 \mathrm{ml}$ diluent -1 is added and sonicate for $30 \mathrm{~min}$ with intermittent swirling. Make up to the volume with diluent-1. Filter the solution through $0.45 \mu$ PVDF membrane filter.

Sample: $444.04 \mathrm{mg}$ sample powder is taken in $500 \mathrm{ml}$ volumetric flask. $350 \mathrm{ml}$ diluent -1 is added and sonicate for $30 \mathrm{~min}$ with intermittent swirling. Make up to the volume with diluent-1. Filter the solution through $0.45 \mu$ PVDF membrane filter.

\section{Preparation of impurities}

Impurities are prepared as mentioned in earlier and all the impurities are injected individually at spec level to check the retention time.

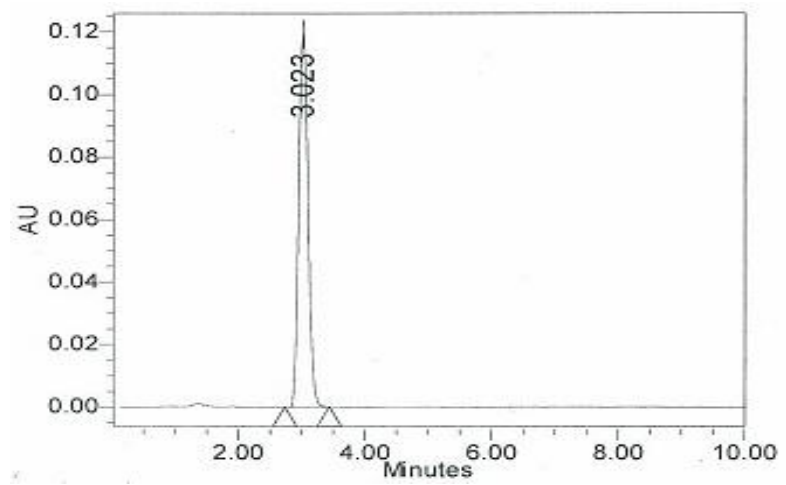

Fig. 1.2 Standard chromatogram

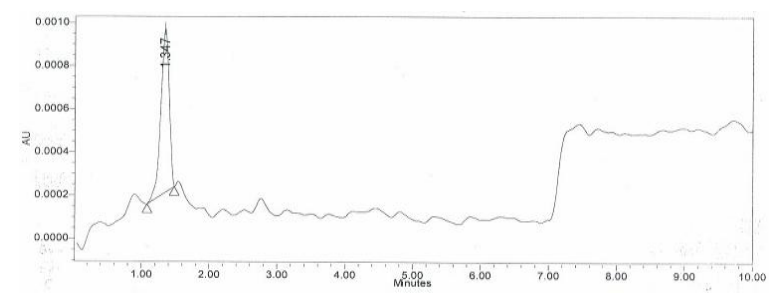

Fig. 1.3 Diluent chromatogram

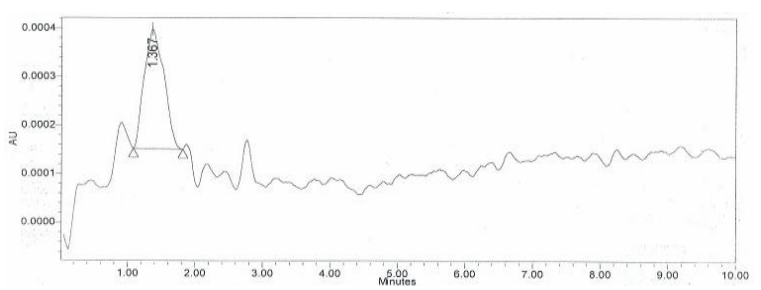

Fig. 1.4 Placebo chromatogram

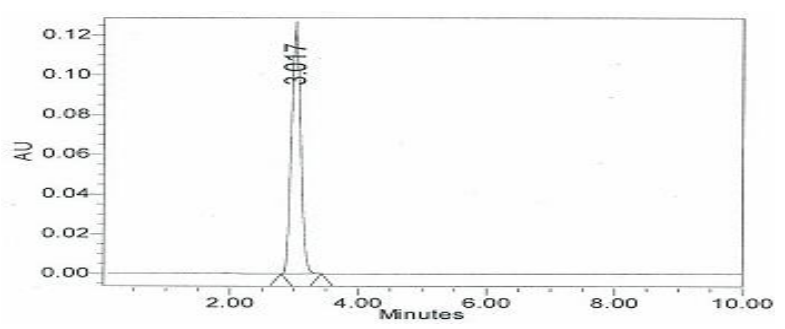

Fig. 1.5 Sample chromatogram

\begin{tabular}{|c|c|c|c|c|c|}
\hline $\begin{array}{c}\text { S. } \\
\text { No. }\end{array}$ & NAME & RT & $\begin{array}{c}\text { Amount } \\
\text { present }\end{array}$ & $\begin{array}{c}\text { Percentage } \\
\text { purity }\end{array}$ & Area \\
\hline 1 & $\begin{array}{c}\text { Metoprolol } \\
\text { sample-50mg }\end{array}$ & 3.02 & 50.58 & 101.2 & 1250890 \\
\hline 2 & $\begin{array}{c}\text { Metoprolol } \\
\text { sample- } \\
100 \mathrm{mg}\end{array}$ & 3.02 & 101.74 & 101.7 & 1254136 \\
\hline
\end{tabular}

\section{Impurity specificity checking}

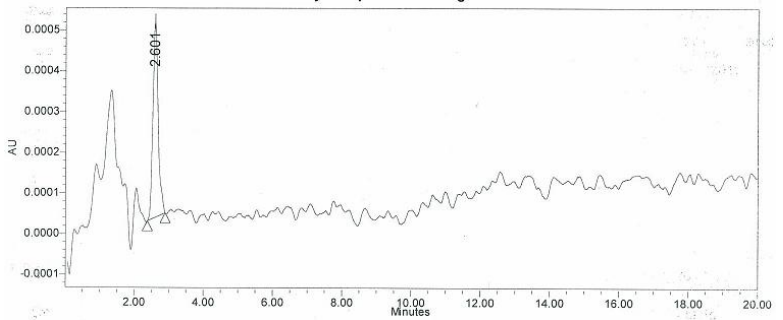

Fig. 1.6 Impurity A

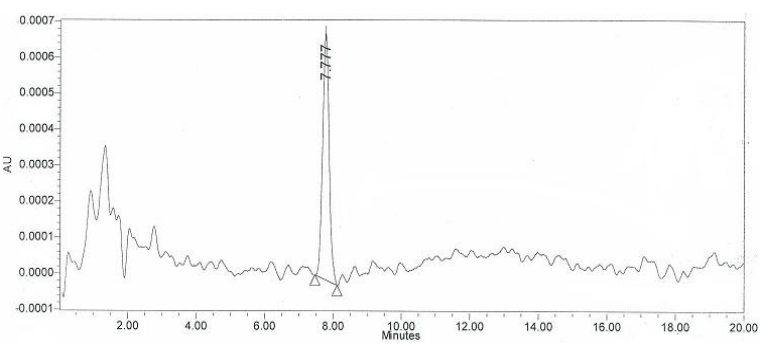

Fig. 1.7 Impurity B 


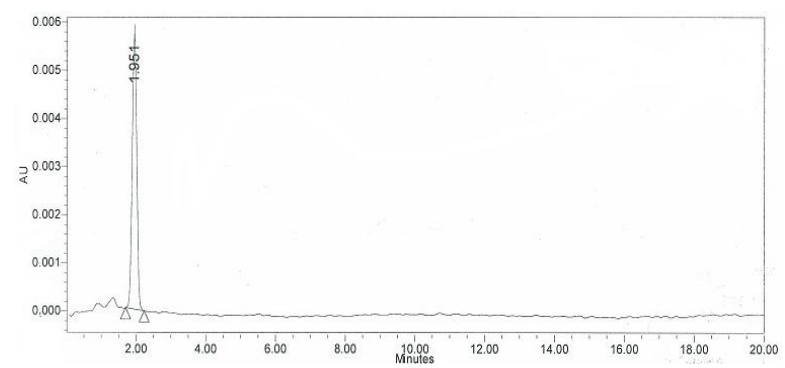

Fig. 1.8 Impurity C

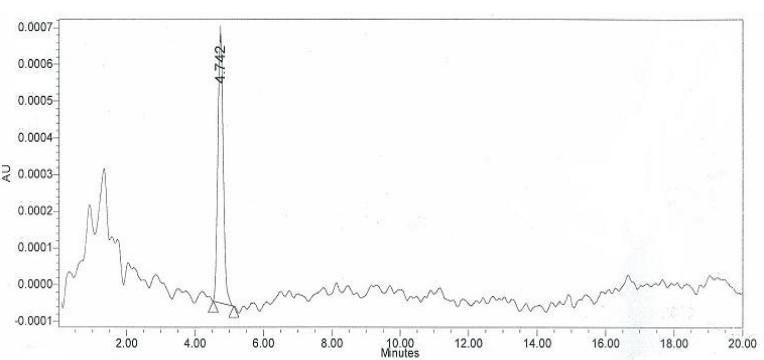

Fig. 1.9 Impurity D

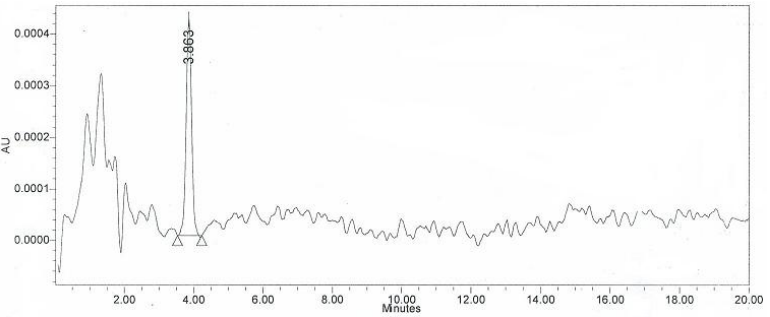

Fig. 1.10 Impurity E

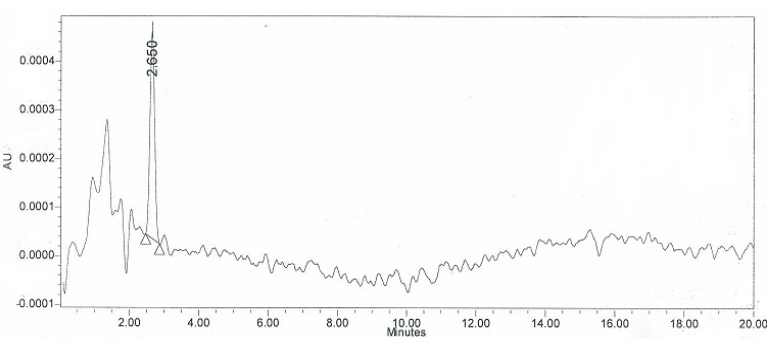

Fig. 1.11 Impurity F

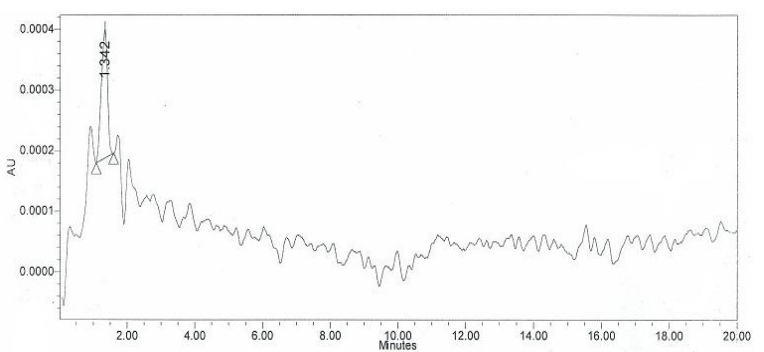

Fig. 1.12 Impurity G

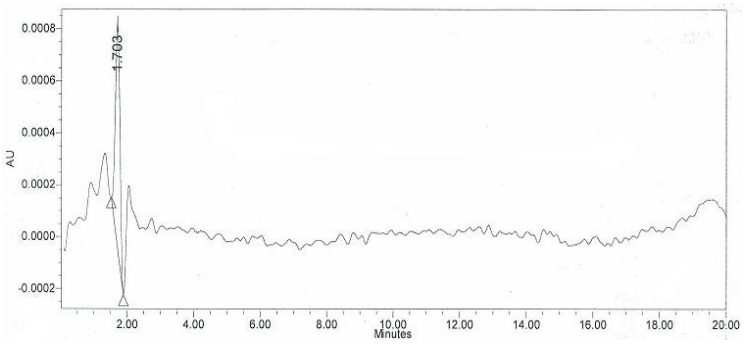

Fig. 1.13 Impurity $\mathrm{H}$

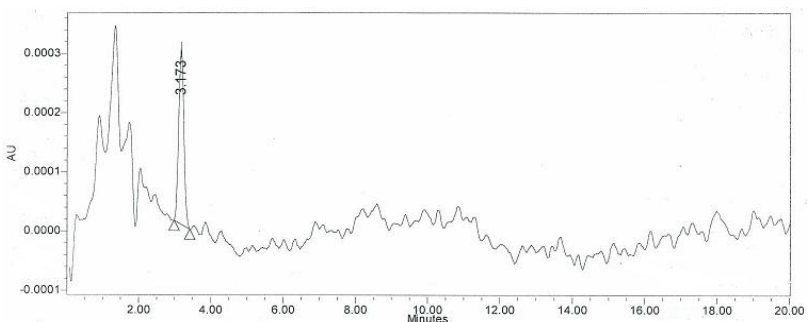

Fig. 1.14 Impurity J

\section{Inference:}

In this mobile phase recovery is better and all impurities were specific with main peak except impurity J. So mobile phase has to be modified to attain specificity with respect to impurity J.

Trail - 2: Modification mobile phase ration to attain specificity towards impurity J.

Mobile phase: $50 \mathrm{ml}$ of $1 \mathrm{M}$ monobasic sodium phosphate $\left(\mathrm{NaH}_{2} \mathrm{Po}_{4}\right)+8.0 \mathrm{ml}$ of phosphoric acid in $900 \mathrm{ml}$ of water. Adjust $\mathrm{pH}$ 3.0 with $1 \mathrm{M}$ OPA or $1 \mathrm{M} \mathrm{NaH}_{2} \mathrm{Po}_{4}$. Make up to $1000 \mathrm{ml}$ with water.

Mix buffer and acetonitrile in ratio $80: 20 \mathrm{v} / \mathrm{v}$

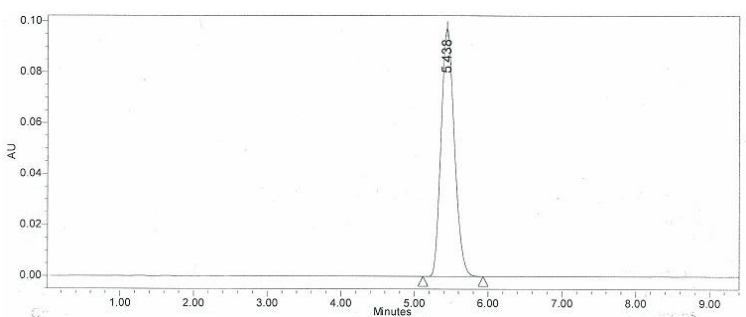

Fig. 1.15 Standard chromatogram

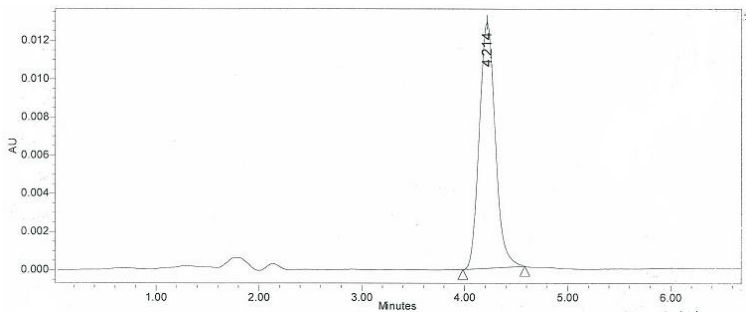

Fig. 1.16 Impurity A

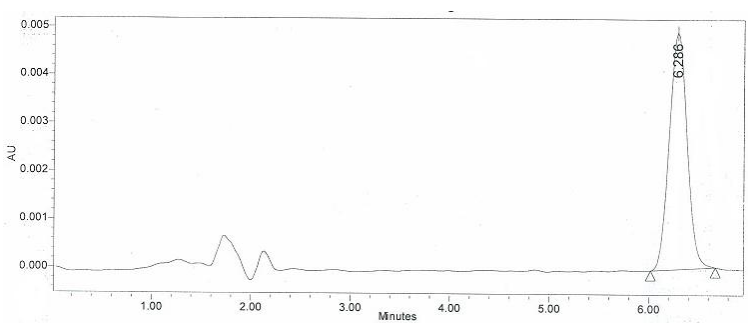

Fig. 1.17 Impurity J

Inference:

Metoprolol tartrate peak is eluted at $5.4 \mathrm{~min}$ and impurity $\mathrm{J}$ is eluted at $6.2 \mathrm{~min}$. Hence by changing the proportion from 75:25 to $80: 20$ of inorganic (buffer) and organic $(\mathrm{ACN})$ ratio, 
Metoprolol peak and impurity J separation is achieved. And recovery seems to be better in $0.1 \mathrm{~N} \mathrm{HCl}$ than in mobile phase. Hence $0.1 \mathrm{~N}$ $\mathrm{HCl}$ is finalized as diluent for Metoprolol tartrate tablets assay.

Finalized Parameters for Metoprolol Tartrate Tablets Assay:

1. Column: Symmetry C18 $(150 \times 3.9) \mathrm{mm}, 5 \mu$

2. Flow rate: $1.0 \mathrm{~mL} / \mathrm{min}$

3. Injection volume: $15 \mu \mathrm{L}$

4. Wave length: $275 \mathrm{~nm}$

5. Column temperature: $25^{\circ} \mathrm{C}$

6. Mobile phase: $50 \mathrm{ml}$ of $1 \mathrm{M}$ monobasic sodium phosphate $(\mathrm{NaH} 2 \mathrm{Po} 4)+8.0 \mathrm{ml}$ of phosphoric acid in $900 \mathrm{ml}$ of water. Adjust pH 3.0 with $1 \mathrm{M}$ OPA or $1 \mathrm{M}$ $\mathrm{NaH} 2 \mathrm{Po} 4$. Make up to $1000 \mathrm{ml}$ with water.

7. Mix buffer and acetonitrile in ratio $80: 20 \mathrm{v} / \mathrm{v}$

8. Diluent 1: $0.1 \mathrm{~N} \mathrm{HCl}$

Further validation has done with the finalized method parameters.

\section{METHOD VALIDATION}

Accuracy:

Sample solutions were prepared using an equivalent amount of placebo and API present in Metoprolol tartrate tablets and analyzed as per methodology. The recovery levels include $100 \%$ of test concentration in duplicate preparation and injected into HPLC.

\begin{tabular}{|c|c|c|c|c|}
\hline \multicolumn{3}{|c|}{ Metoprolol tartrate 50 mg } \\
\hline Concentration & $\begin{array}{c}\text { Amount } \\
\text { recovered } \\
\text { (mg) }\end{array}$ & \% recovery & \multicolumn{2}{c|}{$\begin{array}{c}\text { Statistical } \\
\text { Analysis }\end{array}$} \\
\hline $100 \%$ level -1 & 100.18 & 100.18 & Mean & 100.4 \\
\hline $100 \%$ level - 2 & 100.65 & 100.65 & RSD & $0.3 \%$ \\
\hline \multicolumn{3}{|c|}{ Metoprolol tartrate 100 mg } \\
\hline Concentration & $\begin{array}{c}\text { Amount } \\
\text { recovered } \\
\text { (mg) }\end{array}$ & \% recovery & $\begin{array}{c}\text { Statistical } \\
\text { Analysis }\end{array}$ \\
\hline $100 \%$ level - 1 & 100.11 & 100.41 & Mean & 100.6 \\
\hline $100 \%$ level - 2 & 100.67 & 100.85 & RSD & $0.3 \%$ \\
\hline
\end{tabular}

Acceptance Criteria:

Recovery should be in the range of $95.0 \%$ to $105.0 \%$

Precision:

Assay was performed for six units of Metoprolol tartrate tablets as per test method for both100 and 50mg tablets and injected each solution into HPLC

\begin{tabular}{|c|c|c|c|}
\hline Sample ID & \% Assay & \multicolumn{2}{c|}{ Statistical analysis } \\
\hline 1 & 101.0 & \multirow{2}{*}{ Mean } & \multirow{2}{*}{101.4} \\
\hline 2 & 101.4 & & \multirow{2}{*}{0.24} \\
\hline 3 & 101.2 & SD & \multirow{2}{*}{0.24} \\
\hline 4 & 101.4 & \% RSD & \multirow{2}{*}{101.5} \\
\cline { 1 - 2 } 6 & 101.7 & & \\
\cline { 1 - 2 } & \multicolumn{3}{|c|}{ Method precision for 50mg tablets } \\
\hline
\end{tabular}

\begin{tabular}{|c|c|c|c|}
\hline Sample ID & $\%$ Assay & \multicolumn{2}{|c|}{ Statistical analysis } \\
\hline 1 & 101.4 & \multirow{2}{*}{ Mean } & \multirow{2}{*}{101.5} \\
\hline 2 & 101.6 & & \\
\hline 3 & 101.5 & \multirow{2}{*}{ SD } & \multirow{2}{*}{0.15} \\
\hline 4 & 101.4 & & \\
\hline 5 & 101.6 & \multirow{2}{*}{$\% \mathrm{RSD}$} & \multirow{2}{*}{0.15} \\
\hline 6 & 101.2 & & \\
\hline
\end{tabular}

Acceptance criteria:

RSD of assay result should be not more than $2 \%$

\section{Linearity}

The linearity is determined from $50 \%$ of the ICH reporting level to $150 \%$ of the proposed shelf life specifications of the related substance as a minimum.

\begin{tabular}{|c|c|c|c|c|}
\hline Range & \multicolumn{2}{|c|}{ Dilution in mL } & $\begin{array}{c}\text { Concentration } \\
\text { (ppm) }\end{array}$ & Avg Area \\
\hline $25 \%$ & 1.00 & 20 & 100.52 & 356574 \\
\hline $50 \%$ & 2.00 & 20 & 201.04 & 706467 \\
\hline $75 \%$ & 3.00 & 20 & 301.55 & 1060647 \\
\hline $100 \%$ & 4.00 & 20 & 402.07 & 1407177 \\
\hline $125 \%$ & 5.00 & 20 & 502.59 & 1770275 \\
\hline $150 \%$ & 6.00 & 20 & 603.11 & 2112273 \\
\hline
\end{tabular}

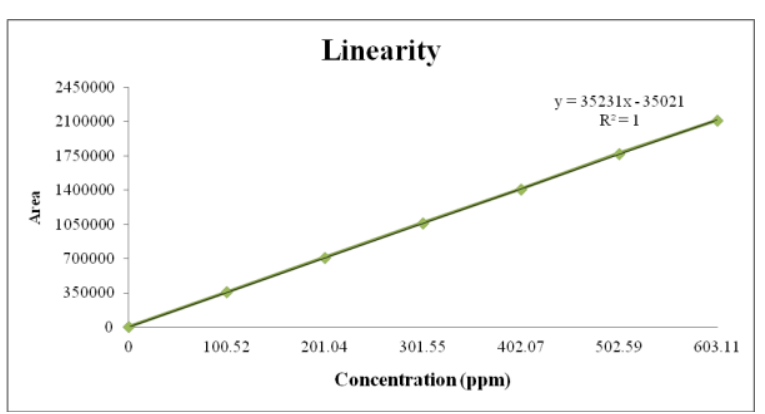

Fig. 1.17 Linearity Graph

\section{Limit of Detection}

From the above Linearity calibration curve Limit of Detection and Limit of Quantitaion were established.

The detection limit (DL) may be expressed as:

$$
\mathrm{DL}=3.3 \mathrm{~s} / \mathrm{S}
$$

Where $\mathrm{s}=$ the standard deviation of $\mathrm{y}$ intercepts of regression lines

$\mathrm{S}=$ the slope of the calibration curve 
By the above calibration curve,

Standard deviation (s) $=658353.789$

Slope $(\mathrm{S})=35231$

$\mathrm{DL}=3.3 \times 658353.789 / 35231=61.67 \mathrm{ppm}$

\section{Limit of Quantitation}

The Quantitation limit (QL) may be expressed as:

$\mathrm{QL}=10 \mathrm{~s} / \mathrm{S}$

Where $s=$ the standard deviation of the response

$\mathrm{S}=$ the slope of the calibration curve

Standard deviation (s) $=658353.789$

Slope $(S)=35231$

$\mathrm{QL}=10 \times 658353.789 / 3523=186 \mathrm{ppm}$

\section{Specificity}

Placebo interference: Placebo solution was prepared in actual concentration of sample and injected into HPLC as per test procedure. Impurity interference: Injected individual impurities for retention time check. Prepared all impurity mixture at spec level and injected into HPLC as per test procedure.

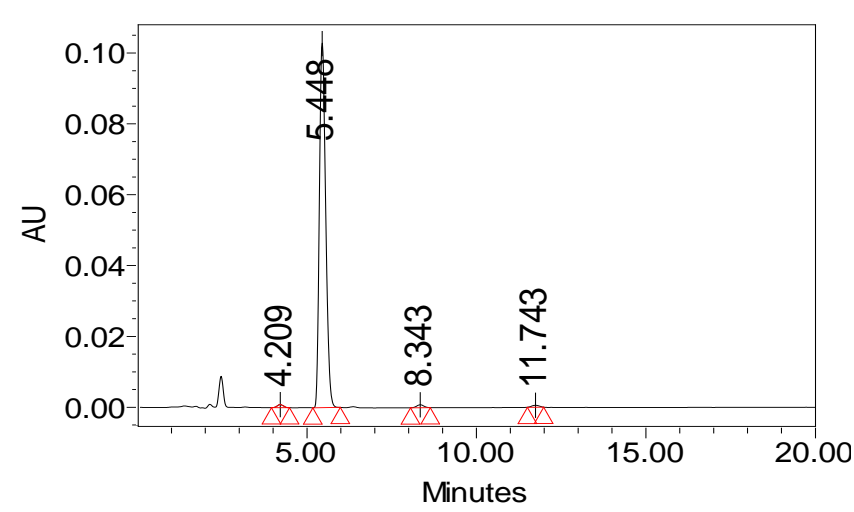

Fig. 1.17 All Impurities spiked chromatogram

\section{Robustness}

For the Metoprolol tartrate tablets, the following parameters are performed

i. Organic $+20 \mathrm{ml}$ and organic $-20 \mathrm{ml}$

ii. Flow rate $+0.2 \mathrm{ml}$ and flow rate $-0.2 \mathrm{ml}$

iii. Column temperature $+5^{\circ} \mathrm{C}$ and Column temperature $-5^{\circ} \mathrm{C}$

iv. Control sample

Standard solution and sample solution were prepared as per methodology and analyses initially as per STP and by changing chromatographic conditions.

\begin{tabular}{|c|c|c|c|c|c|c|c|}
\hline Condition & Variation & Standard & Sample & Impurity A & Impurity B & Impurity C & Impurity D \\
\hline As such & - & 5.43 & 5.44 & 4.21 & 11.74 & 2.46 & 8.34 \\
\hline \multirow{2}{*}{ Organic } & $(-) 20 \mathrm{ml}$ & 7.08 & 7.08 & 3.73 & 3.73 & 3.73 & 10.74 \\
\cline { 2 - 8 } & $(+) 20 \mathrm{ml}$ & 4.15 & 4.15 & 3.38 & 9.51 & 2.20 & 6.41 \\
\hline \multirow{2}{*}{ flow } & $(-) 0.2 \mathrm{ml}$ & 6.78 & 6.77 & 5.25 & 14.69 & 3.06 & 10.41 \\
\cline { 2 - 8 } & $(+) 0.2 \mathrm{ml}$ & 4.59 & 4.59 & 3.55 & 9.82 & 2.08 & 7.01 \\
\hline
\end{tabular}

\begin{tabular}{|c|c|c|c|c|c|c|}
\hline Condition & Variation & Impurity E & Impurity F & Impurity G & Impurity H & Impurity J \\
\hline As such & - & 8.34 & 4.21 & 3.17 & 2.13 & 6.36 \\
\hline \multirow{2}{*}{ Organic } & $(-) 20 \mathrm{ml}$ & 11.44 & 5.32 & 3.50 & 2.36 & 8.70 \\
\cline { 2 - 7 } & $(+) 20 \mathrm{ml}$ & 5.89 & 3.38 & 2.84 & 1.70 & 4.58 \\
\hline \multirow{2}{*}{ flow } & $(-) 0.2 \mathrm{ml}$ & 10.41 & 5.25 & 3.94 & 2.64 & 7.92 \\
\cline { 2 - 7 } & $(+) 0.2 \mathrm{ml}$ & 7.01 & 3.55 & 2.96 & 1.80 & 5.36 \\
\hline
\end{tabular}

\section{SUMMARY AND CONCLUSION}

A rapid, sensitive and selective RP-HPLC method for the determination of Metoprolol tartrate in tablets was developed and validated. Sample preparation was assured by powdered method. Separation occurred on symmetry C18 RP column (150 x $4.6 \mathrm{~mm})$ $5 \mu \mathrm{m}$ with a mobile phase of phosphate buffer pH- 3.0 and Acetonitrile (80:20\% v/v) and detection at $275 \mathrm{~nm}$ in $0.1 \mathrm{~N} \mathrm{HCl}$ as diluents. The standard curve was linear over the concentration range of $100.52-603.11 \mathrm{ppm}$. The lower limit of quantification for
Metoprolol tartrate was $186 \mathrm{ppm}$. This method was successfully applied to the industrial analysis purpose for the analysis of Metoprolol tartrate tablet BP 50, 100mg. The analytical method developed is simple and shows good accuracy, specificity and reproducible. It can be used for the estimation of Metoprolol in Metoprolol tartrate tablets. The separation method developed produce acceptable values of recovery. The chromatogram developed has well resolved peak of Metoprolol without any interference. 


\section{REFERENCES}

1. B. Yilmaz and M. Cavus, Development and validation of gas chromatography-mass spectrometry method for determination of metoprolol in rabbit plasma. International Journal of Pharma and Biosciences. 2010; 1(1): 1-13.

2. Dougles A. Skoog, Analytical Chemistry, 7th edition, Saunders College Publishers, Philadelphia, 1996; 1-15.

3. Indian Pharmacopoeia, Controller of Publications, New Delhi, 1996; Volume-I,

4. Jeffery, G.H. Basselt, J, Vogel's Text Book of Quantitative Chemical Analysis, 5thedn, 1991; 217-235.

5. KV Konna Rao, M.E.B, K .E.V Nagoji, SS Rao, Determination of metoprolol Tartrate by Reverse Phase HPLC Indian journal of pharmaceutical science, Year: 2003; 65(2): 204-206.

6. Lloyd R. Snyder, Joseph J. Kirkland and Joseph L. Glajch, Practical HPLC method development, 2nd edn, 1997; 1-14.

7. M. A. El-Ries, F. M. Abou Attia and S. A. Ibrahim Journal of Pharmaceutical and Biomedical Analysis. 2000; 24(2): 179187.

8. M.Aqil, A.Ali, A.Ahad, Y.Sultana, A. k. Najmi, and N.Saha, A validated HPLC method for estimation of metoprolol in human plasma Acta chromatographica. 2007; 19: 129- 140

9. Mitesh D Phale, and Purnima D Hamrapurkar, A Validated and Simplified RP-HPLC of Metoprolol Succinate from Bulk Drugs, Asian J. Research Chem. 2009; 2(2).

10. Sandy Lindsay, HPLC by open Learning, John Wiley and Sons, 1991; 30-45.
11. Singh Brijesh, Dk Patel and Sk Ghosh, Analysis of metoprolol succinate and hydrochlorothiazide in a tablet formulation in-vitro evaluation of the extended-release performance of metoprolol succinate, the model drug, Tropical Journal of Pharmaceutical Research. 2009; 8(6): 539-543

12. Singh brijesh, Dk Patel and Sk Ghosh, Development of reverse-phase HPLC method for simultaneous analysis of metoprolol succinate and hydrochlorothiazide in a tablet formulation, Tropical Journal of Pharmaceutical Research. 2009; 8(6): 539-543.

13. Sohan S chitlange, Mohammed imran, Dinesh M sakarkar; RP-HPLC method for simultaneous estimation of amlodipine and metoprolol in tablet formulation. Asian Journal of Pharmaceutics. 2008; 232-234.

14. USP 25-National Formulary 20 (2002).

15. Validation of Analytical Procedures: ICH Harmonized Tripartite Guideline for Residual Solvents, step 4, 17 July 1997.

16. Validation of Analytical Procedures: Methodology, ICH Harmonized tripartite Guideline, 1996, 1-8

\section{How to cite this article:}

B. Nageswara Rao et. al.. Development and validation of reverse phase high performance liquid chromatographic method for the estimation of metoprolol tartrate tablets 50, $100 \mathrm{mg}$. Int. J. Adv. Pharm. Biotech., 2015; 1(2): 25-30. 